\title{
THE CONCEPT OF THE LUXURY BRANDING IN SAMSUNG GALAXY S6 EDGE SERIES THROUGH TRIADIC MODES OF SIGN
}

\author{
Anggakara, T. ${ }^{1}$ and Gunawan, S. $^{2}$ \\ 1,2 English Department, Faculty of Letters, Petra Christian University, Siwalankerto 121-131, Surabaya \\ 60236, East Java, INDONESIA \\ E-mails: anggakarapaksi@gmail.com ; samuelgunawan@ymail.com
}

\begin{abstract}
This thesis mainly deals with the iconisation of signs and naturalisation process in order to reveal the way Samsung Galaxy S6 Edge is naturalised as a luxury product. This thesis also involves analysis of the luxury branding concept through the analysis of a product which conceptualises its advertisement using the concept of luxury identifiers. The focus of the writer's analysis is the advertisements themselves as the writer will use the triadic modes of signs, naturalisation process, and the concept of luxury identifiers which also involves process of signification, and metaphor in its analysis. Those theories will help the writer in analysing the meaning of the advertisement first, and then figure out the aim of the luxury branding strategy in the product, then figure out how the expressions are used in the luxury concept of advertisement. The writer analyses the advertisement of Samsung Galaxy S6 Edge which was published in 2015. From the analysis, the writer found out that the luxury branding strategy of Samsung Galaxy S6 Edge utilises naturalisation process to naturalise the luxury identity of Samsung Galaxy S6 Edge which is a masstige product. Using that as a basis, the expressions in the advertisement focus on selling the idea that Samsung Galaxy S6 Edge is a luxury product which is an innovative idea designed for professionals and to display superiority within the social group. Samsung Galaxy S6 Edge aims to provide the user with a display of social superiority within the social group through the consumption of Samsung Galaxy S6 Edge. In that regards, the user will be seen as a person who is wealthy, stand out in terms of taste, and a professional who is fully aware of the technology.
\end{abstract}

Key Words: Luxury Branding Strategy, Naturalisation Process, Process of Signification, Icon, Index, Symbol, Metaphor.

\section{INTRODUCTION}

Advertisement has never been a mere communication medium which purpose is limited only to introduce or to promote some products. Advertisement is more than that; its usage is complex, not just a mere marketing tool designed only to inform people about the product and persuade them to buy the product. In addition, advertisement can also be used to imprint certain image and/or perspective to the mind of the audience regarding the product and/or the company. For instance, some cigarette companies such as Phillip Morris. inc which owns Marlboro, has been using advertisements in that regards to build up the image of masculinity in smoking Marlboro cigarette. In that way, people regards smoking Marlboro cigarette as a gentlemanly activity. The practice of using advertisement that way underlines Harris's (2004) statement which explains that advertisements tries to affect or alter the reality of the audience, in the sense that advertisement is designed to establish a new image or point of view regarding a certain product. In that regards, advertisements are turning people towards a product or service by providing a positive feeling and information that goes beyond simply calling people's attention into it (Percy, 2005, p.4).

This study seeks to describe the way Samsung Galaxy S6 Edge is naturalised as a luxury product. In that sense, this study focuses on the theory of triadic modes of the sign introduced by Peirce to interrogate the association between signs since Peirce's triadic modes of the sign talks about differences in "modes of relationship" or "types of relationship" between the signifier and the signified. As its name implies, Peirce's triadic modes of the sign consists of three types of relationship between signs; symbol/symbolic, icon/iconic, and index/indexical. Symbolic is the relationship of the sign which must be agreed upon and learned first to understand its relationship since the signifier does not resemble the signified at all because the signified is fundamentally arbitrary or purely conventional for instance traffic lights, red colour (signifier) in the traffic lights is a symbol of stop (signified). On the other hand, iconic/icon refers to the relationship between 
signifier and signified where the signifier resembles the signified in a certain quality (shape, scent, taste, etc) for instance scale-model (signifier) as the icon of the real thing (signified). Unlike the first two, indexical refers to the relation between signifier and signified where the signifier and the signified are directly connected in some way, for example watch or clock (signifier) is an index of time of the day (signified). Understanding about Peirce's triadic modes of the sign is a priority in this study as it will create a better understanding in the association between signs or between signifier and signified. More importantly, it is because the concept of luxury branding is based on the triadic modes of the sign as the concept of luxury branding makes the product to iconise its owner success by showing off its luxury qualities through the advertisements or other marketing tools.

Samsung Galaxy S6 Edge is the latest product of Samsung Galaxy S Series which is imbued with luxury theme and is regarded as a competitor of Apple's iPhone which is regarded as world's best smartphone. However, as this research analyses advertisement which is the mirror of the actual product, the luxury concept of Samsung Galaxy S6 Edge must be defined further in order to grasp the concept of the expression used in the luxury branding and its aim. Thus, in order to further define the concept and the aim of luxury branding within the advertisement of Samsung Galaxy S6 Edge, the luxury value itself is going to be further defined. Understanding the prestigious value of Samsung Galaxy S6 Edge through this definition is essential to grasp the authenticity of the representation of luxury in Samsung Galaxy S6 Edge. According to literature, there are two kinds of luxury nowadays; the (traditional) luxury which tend to focus on the power of brand based on heritage, craftsmanship, limited distribution, and the new luxury or mass prestige/masstige which tend to focus on seasonality, travel, and innovation.

Heritage, craftsmanship, premium pricing, and rarity are tangible aspects which luxury brands offers. However, luxury brands also reaches beyond the tangible towards the perception of individual and social (Berthon, Pitt, Parent\&Berthon, 2009). The personal value is a crucial component of luxury goods where the consumers purchase these luxury goods for experiences of 'fun, feelings, pleasure, excitement, and fantasy' (Hagtvedt \& Patrick, 2009, p. 610 as cited in Adebeshin, 2015). Consumers often associate luxury with a dream, or a dream world (Dubois \& Paternault, 1995 as cited in Adebeshin, 2015), and when discussing luxury goods they use hedonic terms such as "opulent", "pleasing to the touch and eye" and designed to "indulge and delight" (Tynan et al., 2010, p. 1160). Hedonism in luxury involves the sensual and the magical that 'makes life beautiful'. By consuming luxury goods the consumer sought to be provided with "exclusivity, recognition, access to privileged information and prestige (Tynan et al., 2010, p. 1161). It is the "dream" that consumer hopes to experience through the consumption of luxury brands. The social value of luxury is defined as a perceived utility individuals acquire with products or services recognised within their own social group(s). Along the social dimension, luxury goods give perceived status on the conspicuous-driven consumer. A brand's exclusivity and rarity boosts perceived uniqueness where the consumers can demonstrate personal taste, stand out, and avoid similar consumption within the social group (Vigneron \& Johnson, 2004, p. 490). Furthermore, the consumption of luxury goods in the society offers a "social display of superiority" (Roper, Caruana, Medway, \& Murphy, 2013 as cited in Adebeshin, 2015) and a "sense of an extended self" (Belk, 1988 as cited in Adebeshin, 2015). In conclusion, luxury is associated with an affluent lifestyle, thus, luxury brand consumption is a signifier of an affluent lifestyle. The value of the public consumption of luxury lies in its quality, its sophistication and craftsmanship, demonstrating taste and wealth (Adebeshin, 2015, p.20).

The second category of luxury is the new luxury or masstige which is an abbreviation for "mass prestige". Like its name, mass prestige is a revolutionary product to make luxury goods available to masses with the purpose of attaining the benefits of luxury value at a lower costs. In that regards, masstige also refers to goods that are not necessarily rare or manufactured in low volume; these goods acquire the luxury label due to design, additional services or the aura created by the brand (Castelli, 2013, p. 832 as cited in Adebeshin, 2015). Some world-class brands that fall into this category are: Victoria's Secret, Calvin Klein, BMW, Michael Kors, Fossil, etc. Different from luxury brands in which the product itself is alluring in the sense of material quality and craftsmanship, consumers of masstige brands are more interested in the image associated with the brand rather than the products itself (Silverstein\&Fiske, 2003a as cited in Adebeshin, 2015). In that sense, new luxury or masstige serves two primary purposes for consumers: to provide an opportunity to indulge in personal pleasure (luxury for self); and to demonstrate success (luxury for others). 
Masstige brands, therefore, "provide a language and nonverbal method of self-expression and social dialogue" (Granot, Russell, 2013, p. 38 as cited in Adebeshin, 2015).

\section{METHODS}

This research was conducted using Krippendorff's (2004) qualitative content analysis method combined with Schreier's (2012). Krippendorff defined content analysis as a research technique for making replicable and valid inferences from texts (or other meaningful matter) to the context of their use (Krippendorff, 2004, p.18). Since this research sought to describe the concept of expressions in the luxury branding of Samsung S Series in a systematic way, content analysis is the most suitable research technique to approach the matter as content analysis technique provides new insights, increases a researcher's understanding of particular phenomena, and informs practical actions. In addition, qualitative content analysis is the most suitable approach to analyse the meaning of an advertisement through the systematic practice of describing the meaning of qualitative material (Schreier, 2012, p.1). Furthermore, the most elementary reasoning behind the use of qualitative content approach is because the data were in the form of images with several texts on it and not in the form of numeric data, which makes qualitative analysis form more effective in reaching the research goals.

Data analysis was the process after the writer had done the data collection completely. Some steps that the writer used in order to unveil the concept of the expression in the advertisements includes finding their denotative meaning in the dictionary (for verbal expression), find the association with the other expression, and find the aim of the use of the object of expression. In this analysis, both expressions correlate, and support each other in order to fully develop the meaning of the advertisement. Therefore, each one of them cannot be independent from one another and must be analysed while paying attention to the other expression by relating them together. The use of Peirce's triadic modes of the sign and luxury/masstige identifier concept in the analysis contribute much in reaching the goal of the research as the concept of the two theories give the writer new insights in explaining some phenomena in the analysis. The conclusion of this research unveils how Samsung Galaxy S6 Edge is naturalised as a luxury product from semiotics perspective.

\section{FINDINGS AND DISCUSSION}

In analysing the advertisement, the writer found several advertising cues within the advertisement of Samsung Galaxy S6 Edge. Those advertising cues are the keys in building the image surrounding Samsung Galaxy S6 Edge. The advertising cues within the advertisement are identified as denotative meaning and connotative meaning. Denotative meaning in the advertisement is identified through understanding the main idea of the texts, the purpose of the text/picture. On the other hand, connotative meaning requires deeper understanding such as paying attention to the association of certain colour or idea within the advertisement as connotative meaning is hidden in the connotative level of signification. The denotative meaning and the connotative meaning within the advertisement of Samsung Galaxy S6 Edge are listed as follows.

\begin{tabular}{|c|c|}
\hline Denotative Meaning & Connotative Meaning \\
\hline Advanced Technology & Innovation \\
\hline Novelty & Following the trend \\
\hline Youth & Exclusivity \\
\hline Luxury/Wealth & Achievement \\
\hline Professionalism & \\
\hline Sense of identity &
\end{tabular}




\begin{tabular}{|c|c|}
\hline Denotative Meaning & Connotative Meaning \\
\hline Travel & Adventure \\
\hline Simplicity & Sophistication \\
\hline Elegance/ Beauty & Timelessness \\
\hline Classic & Craftsmanship \\
\hline Durability & \\
\hline
\end{tabular}

Table 1 : Advertising cues in Samsung Galaxy S6 Edge advertisement

In his research, Adebeshin pointed out that luxury brands tend to have several unique connotative meanings in the advertisement which are timelessness, heritage, authenticity and prestige unseparated from the reality that luxury brands have limited production and distribution area in the sense to create a scarcity of product (Adebeshin, 2015, p.68). In that sense, luxury brands aim to be perceived as prestigious art in the form of authentic brands based on heritage with timeless products and artistic craftsmanship. On the other hand, masstige brands tend to implicitly focus on the seasonality, lifestyle, adventure, and renewal while adopting some of luxury brand concepts such as exclusivity, achievement, pride, sophistication (Adebeshin, 2015, p.68). By underlining those concepts, masstige brands aim to sell the concept of trend to its audience, making the audience feel stylish, trendy, young, and adventurous. To further understand the naturalisation process in Samsung Galaxy S6 Edge advertisement, the writer felt the importance of unveiling the luxury identity of Samsung Galaxy S6 Edge as a part of the naturalisation process and to give further understanding regarding the aim of the luxury branding itself. The analysis of the luxury identity of Samsung Galaxy S6 Edge began with the grouping of advertising cues found in Samsung Galaxy S6 Edge as listed in table 4.1 according to its respective brand characteristics based on Adebeshin's studies (Adebeshin, 2015, p.64).

Based on the table above (Table 1), it could be concluded that Samsung Galaxy S6 Edge is a luxury product which is categorised under the masstige brand product which tries to project itself as traditional or genuine luxury product. The masstige brand identity of Samsung Galaxy S6 Edge could be identified from its distinctive meanings which mostly are the unique characteristics of masstige brand product such as novelty, following the trend, etc. Moreover, the concept of the advertisement which stresses on the advanced technology concept, youthful activity (gaming, taking pictures, making videos), and travel are also within the domain of masstige brand concept which imply on Innovation, Following the trend, and Adventure.

The luxury branding strategy of Samsung Galaxy S6 Edge which creates the highest brand value and pricing power is a product of naturalisation process. As a product of naturalisation process, the luxury branding strategy of Samsung Galaxy S6 Edge is aimed to cover the luxury identity of Samsung Galaxy S6 Edge; to make people unaware that Samsung Galaxy S6 Edge is a masstige brand product. In order to do so, the luxury branding strategy of Samsung Galaxy S6 Edge adopts some concepts involving the use of certain colour/design/language such as classic concept,gold colour, etc which is unique to traditional luxury brand to associate Samsung Galaxy S6 Edge with wealth, exclusivity, and sense of achievement. Not only limited to associate Samsung Galaxy S6 Edge with wealth, exclusivity, and sense of achievement, Samsung Galaxy S6 Edge also tries to imply good craftsmanship and durable material from the use of certain colour in the design of the actual product. By adopting those unique characteristics of traditional luxury brands through naturalisation process in the luxury branding, the consume of the product is aimed to bring pleasure, establish self-esteem, and to display "the social superiority" of the owner within the social group.

In its concept, Samsung Galaxy S6 Edge as a masstige brand product appeals its audience by stressing on the idea that Samsung Galaxy S6 Edge is the advanced technology, implying that Samsung Galaxy S6 Edge is an innovative product to trigger the sense of novelty which affect the 
impulsive buying decision within the mind of audiences. Moreover, Samsung Galaxy S6 Edge is selling the idea of youth by displaying some youthful activities such as gaming, taking pictures, making videos, etc to indulge the audience as if they are following the trend, making them feel stylish, and trendy by consuming the product. Moreover, Samsung Galaxy S6 Edge adopt the characteristics of luxury product such as sense of identity, sense of wealthy, sense of elegance, and sense of classic within its advertising concept to associate Samsung Galaxy S6 Edge with luxury/wealth, and exclusivity in order to display social superiority within social groups. Those adopted ideas from traditional luxury product are shown in the advertisement in the form of use of language to address the customer and their needs to trigger the sense of identity. Besides language, Samsung Galaxy S6 Edge also play with the use of colour such as black, white, and gold which signifies classy and luxury to adopt the signification of those colours in the naturalisation process, to give the implication that Samsung Galaxy S6 Edge is a signification of luxury, classy, and elegance.

Since Samsung Galaxy S6 Edge is a masstige brand product which mostly utilises naturalisation process in its advertisement in the form of luxury branding, therefore, the finished product itself is a also a part of naturalisation process. The use of certain colour such as gold to imply good craftsmanship, durable material in its design does not mean that the actual product is made from real valuable gold although the product is made from metal which considered durable compared to other products. However, the gold colour is there only to give the actual product a touch of luxury quality to please the eye, bring pleasure, build self-esteem, demonstrate social superiority, and personal taste of the owner in the social group.

\section{CONCLUSION}

Through the luxury branding strategy, Samsung Galaxy S6 Edge aims to make audiences become unaware of the luxury identity of Samsung Galaxy S6 Edge which is a masstige brand product. Instead, Samsung Galaxy S6 Edge aims to make audiences fully aware that Samsung Galaxy S6 Edge is a luxury smartphone in par with Apple's iPhone, making Samsung Galaxy S6 Edge a direct competitor of Apple's iPhone because of its advanced features, specifications, and designs. By using a certain colour, concept, design, and language which are exclusive to traditional luxury brand product, Samsung Galaxy S6 Edge aims to be seen as "opulent" which is "pleasing to the touch and eye" (Tynan et al., 2010, p. 1160). Through its advanced features and specifications, Samsung Galaxy S6 Edge aims to be seen as an innovative product which encourages its consumer to use its feature to the fullest. In other words, Samsung Galaxy S6 Edge encourages its consumer to be fully aware of the technology. As a result of those aims, Samsung Galaxy S6 Edge aims that the user will display social superiority within the social group through consuming Samsung Galaxy S6 Edge in the sense that the user will be seen as a person who is wealthy, stand out in terms of taste, and a professional who is fully aware of the technology.

\section{REFERENCES}

Adebeshin,K. (2015). Exploring Symbolism in Masstige Brand Advertising Within the Discursive Content of Luxury: A Semiotic Analysis. Unpublished Thesis.Auckland: Auckland University of Technology.

Berthon, P., Pitt, L., Parent, M., \& Berthon, J. (2009). Aesthetics and ephemerality: Observing and preserving the luxury brand. California Management Review, 52(1), 45-66. doi: 10.1525/cmr.2009.52.1.45.

Harris, R. (2004). A cognitive psychology of mass communication. London: Lawrence Erlbaum Associates, Inc.

Krippendorff, K. (2004). Content Analysis: an introduction to its methodology 2ed. California: Sage Publication

Peirce, C. (1931-58) Collected Papers (ed. Charles Hartshorne and Paul Weiss, 1932; Burks, 1958; vol. 8, Reviews, Correspondence and Bibliography, ed. William A. Burks,

Percy, L \& Elliot, R. (2005). Strategic advertising management. NewYork: Oxford University Press 
Schreier, M. (2012). Qualitative Content Analysis in Practice. Los Angeles: SAGE Publications, Ltd.

Tynan, C., McKechnie, S., \& Chhuon, C. (2010). Co-creating value for luxury brands. Journal of Business Research, 63(11), 1156-1163.doi: 10.1016/j.jbusres.2009.10.012

Vigneron, F., \& Johnson, L. W. (2004). Measuring perceptions of brand luxury. Journal of Brand Management, 11(6), 484-508. doi: 10.1057/palgrave.bm. 2540194 


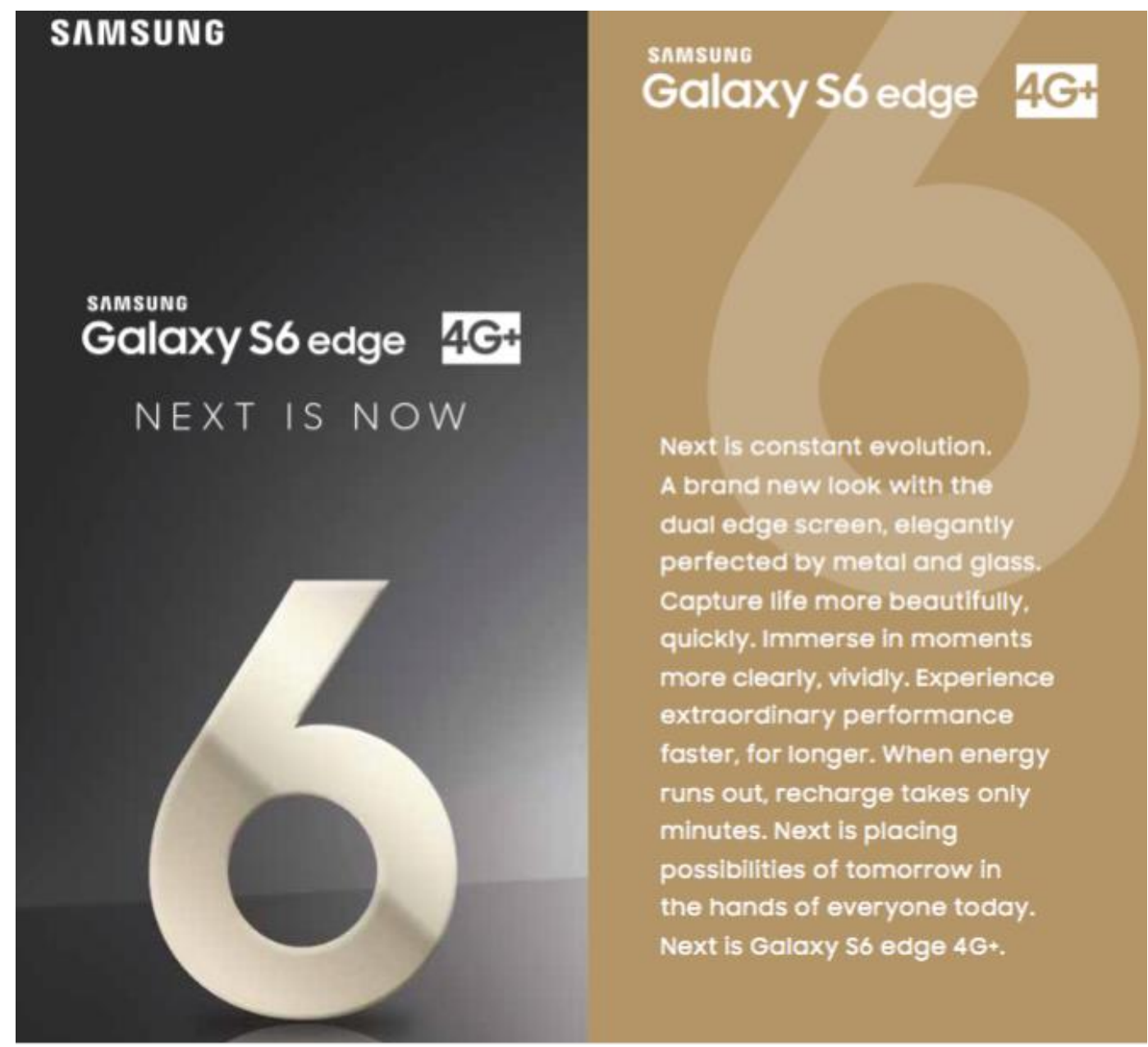

\section{APPENDIX}

Next is treating yourself right.

$\Rightarrow$ GaLAXYLie aik 201 fle privilogos

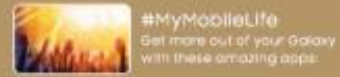

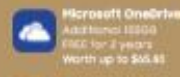

(C)

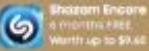

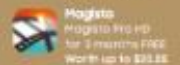

do
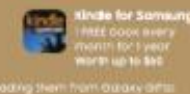

SAMSUNG

PREMIUM CARE

pacaiseogreat proauct Beserves

greater pracection kt cony sses, givo yout

(7t) sessen mispot

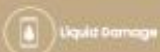

01 Elevated Design

(a)

(a) $\sqrt{15}$

Introducing she ouar edges screen drossed in coot aeminlum and urm durobia corning' Gorilio* Giass? Win synomie rethetwe surtoce on
the back and curved imimarsion on ine tront Peopie Eoge takes abvortag of the angins screen to alert you subthy whiccurour coceda notitications when your foveurite contacts cal

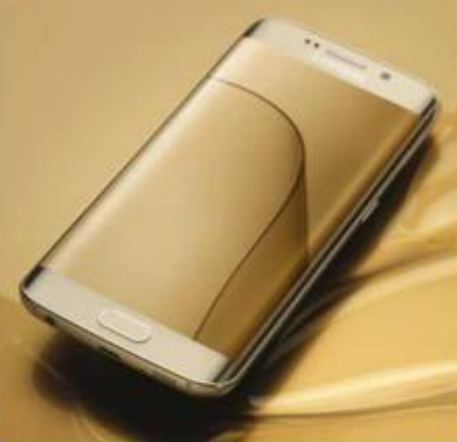

148 